\title{
Дослідження показників функціонального стану тактильного аналізатора у дітей середнього шкільного віку з вадами зору
}

\author{
Ліліана Рядова
}

Харківська державна академія фозичної культури, Харків, Україна

Mета: визначити показники фуункціонального стану тактильної сенсорної системи в учнів середніх класів з вадами зору.

Матеріал і методи: показники тактильної чутливості визначалися за методом естезіометрії. В дослідженні прийняли участь школярі середніх класів з вадами зору комунального закладу «Харківська спеціальна загальноосвітня школаінтернат I-III ступенів № 12» Харківської обласної ради для дітей з вадами зору.

Результати: розглядалисяпоказники тактильноїчутливості 3-ої фаланги середнього пальця кисті та середини долоні у дітей середнього шкільного віку з вадами зору.

Висновки: виявлено, що найкращі показники відчуття дотику на 3-ій фраланзі середнього пальця кисті спостерігалися у хлопиів 10-го та дівчат 7-го класів; середини долоні - у хлопців 6-го та дівчат 9-го класів.

Ключові слова: вади зору, відчуття дотику, діти, середній шкільний вік, тактильна чутливість, фрункціональний стан тактильного аналізатора.

\section{Вступ}

Тактильна сенсорна система дає інформацію про амплітуду рухів і зіткнення тіла зі спортивними снарядами й інвентарем, відіграє важливу роль в координації рухів, сприйнятті простору та орієнтуванні в ньому, допомагає точно визначити швидкість бігу [9, 11].

За допомогою тактильного сприйняття діти з вадами зору отримують різноманітний комплекс відчуттів - дотик, тиск, рух, тепло, холод, вібрації, лоскот, біль та свербіння. Це дає їм можливість визначати форму, розміри, фрактуру предметів, характер матеріалу, з якого вони зроблені, деформацію тіл, встановлювати пропорції та їх відносини [5].

Дітям з вадами зорутактильний аналізатордопомагає у створенні повноцінного образу в процесі навчання, орієнтування у просторі, пізнання навколишнього світу [12].

На думку Т. В. Ножкіної, І. А. Півоварової, Н. В. Прусової [7], оптимальний функціональний стан тактильного аналізатора може компенсувати порушення зору, оскільки відіграє важливу роль у процесі сприйняття та аналізу різних видів зовнішніх і внутрішніх подразників і у формуванні рухів.

Питання стану окремих функцій сенсорних систем у дітей без порушень зору дошкільного віку вивчала О. К. Моісеєнко [6], у дітей молодшого шкільного віку - І. П. Масляк [10], у дітей середнього шкільного віку - І. О. Кузьменко [4], у спортсменів-волейболістів - А. С. Ровний [8], А. Абдулаев, О. К. Моісеєнко [1]. Однак робіт, присвячених дослідженню показників функціонального стану тактильного аналізатора у дітей середнього шкільного віку з вадами зору немає.

Все вищевикладене і свідчить про актуальність дослідження.

Зв'язок дослідження 3 науковими програма-ми, планами, темами. Дослідження проводилося відповідно до Тематичного плану науково-дослідної роботи Харківської державної академії фрізичної культури на 2013-2015 рр. за темою 3.5.29. «Теоретичні та прикладні основи побудови моніторингу фрізичного розвитку, фрізич- ної підготовленості та фрізичного стану різних груп населення» (номер державної реєстрації 0113U004615) і на 2016-2020 рр. за темою «Вдосконалення процесу фізичного виховання в навчальних закладах різного профілю» (номер державної реєстрації0115U006754).

Мета дослідження: визначити показники функціонального стану тактильної сенсорної системи в учнів середніх класів з вадами зору.

\section{Матеріал і методидослідження}

Дослідження проводилося на базі комунального закладу «Харківська спеціальна загальноосвітня школаінтернат I-III ступенів № 12» Харківської обласної ради для дітей з вадами зору. В ньому брали участь 117 учнів середніх класів. Для досягнення мети дослідження використовувалися такі методи: теоретичний аналіз і узагальнення науково-методичної літератури, метод естезіометрії та статистичні методи.

\section{Результати дослідження}

Функціональний стан тактильного аналізатора у дітей середнього шкільного віку з вадами зору визначався за методом естезіометрії. Досліджувалися показники відчуття дотику на 3-ій фаланзі середнього пальця кисті та середини долоні. Норми показників тактильної чутливості 3-ої фаланги середнього пальця кисті відповідають 2,2 мм, середини долоні - 8,9 мм [2].

Аналіз показників тактильної чутливості показав, що результати відчуття дотику на 3-ій фаланзі середнього пальця кисті кращі у хлопців 10-го та дівчат 7-го класів; середини долоні - у хлопців 6-го та дівчат 9-го класів. Слід відмітити, що у школярів 6-го, у хлопців 5-го та дівчат 10го класів спостерігалися однакові показники тактильної чутливості 3-ої фаланги середнього пальця кисті (табл. 1).

Розглядаючи результати тактильної чутливості 3-ої фаланги середнього пальця кисті в учнів у статевомуаспекті, виявлено, що у хлопців вони, здебільшого, кращі, 


\section{СЛОБОЖАНСЬКИЙ НАУКОВО-СПОРТИВНИЙ ВІСНИК:}

\section{Матеріали XIX Міжнародної науково-практичної конференції «Фізична культура, спорт і здоров'я: стан, проблеми та перспективи»}

Таблиця 1

Показники тактильної чутливості (мм) у хлопців і дівчат середнього шкільного

віку з вадами зору у статевому аспекті

\begin{tabular}{|c|c|c|c|c|c|c|c|c|c|c|}
\hline \multirow{3}{*}{$\begin{array}{l}0 \\
\frac{\pi}{5} \\
\text { ํ. }\end{array}$} & \multicolumn{3}{|c|}{ Хлопці } & \multicolumn{3}{|c|}{ Дівчата } & \multirow{3}{*}{$\mathrm{t}_{1,3}$} & \multirow{3}{*}{$p$} & \multirow{3}{*}{$\mathrm{t}_{2,4}$} & \multirow{3}{*}{$p$} \\
\hline & $\mathrm{n}$ & $\begin{array}{l}\text { 3-я фраланга } \\
\text { серед-нього } \\
\text { пальця кисті }\end{array}$ & $\begin{array}{c}\text { Середина } \\
\text { долоні }\end{array}$ & \multirow[t]{2}{*}{$n$} & $\begin{array}{l}\text { 3-я фраланга } \\
\text { серед-нього } \\
\text { пальця кисті }\end{array}$ & $\begin{array}{c}\text { Середина } \\
\text { долоні }\end{array}$ & & & & \\
\hline & & \multicolumn{2}{|c|}{$\bar{X}_{ \pm \mathrm{m}}$} & & \multicolumn{2}{|c|}{$\bar{X}_{ \pm \mathrm{m}}$} & & & & \\
\hline 5 & 15 & $\begin{array}{c}3,39 \pm \\
0,04\end{array}$ & $\begin{array}{c}9,51 \pm \\
0,07\end{array}$ & 6 & $\begin{array}{c}3,43 \pm \\
0,05\end{array}$ & $\begin{array}{c}9,45 \pm \\
0,10\end{array}$ & 0,77 & $>0,05$ & 0,54 & $>0,05$ \\
\hline 6 & 15 & $\begin{array}{c}3,39 \pm \\
0,04\end{array}$ & $\begin{array}{c}9,47 \pm \\
0,14\end{array}$ & 10 & $\begin{array}{c}3,44 \pm \\
0,04\end{array}$ & $\begin{array}{c}9,55 \pm \\
0,20\end{array}$ & 0,78 & $>0,05$ & 0,36 & $>0,05$ \\
\hline 7 & 6 & $\begin{array}{c}3,47 \pm \\
0,07\end{array}$ & $\begin{array}{c}9,55 \pm \\
0,23\end{array}$ & 16 & $\begin{array}{c}3,31 \pm \\
0,04\end{array}$ & $\begin{array}{c}9,79 \pm \\
0,24\end{array}$ & 1,97 & $>0,05$ & 0,77 & $>0,05$ \\
\hline 8 & 15 & $\begin{array}{c}3,33 \pm \\
0,05\end{array}$ & $\begin{array}{c}9,75 \pm \\
0,22\end{array}$ & 6 & $\begin{array}{c}3,32 \pm \\
0,08\end{array}$ & $\begin{array}{c}9,65 \pm \\
0,16\end{array}$ & 0,19 & $>0,05$ & 0,40 & $>0,05$ \\
\hline 9 & 8 & $\begin{array}{c}3,24 \pm \\
0,04\end{array}$ & $\begin{array}{c}9,50 \pm \\
0,18\end{array}$ & 6 & $\begin{array}{c}3,33 \pm \\
0,05\end{array}$ & $\begin{array}{c}9,43 \pm \\
0,16\end{array}$ & 1,48 & $>0,05$ & 0,30 & $>0,05$ \\
\hline 10 & 6 & $\begin{array}{c}3,13 \pm \\
1,11\end{array}$ & $\begin{array}{c}10,20 \pm \\
0,43\end{array}$ & 8 & $\begin{array}{c}3,44 \pm \\
0,04\end{array}$ & $\begin{array}{c}9,75 \pm \\
0,11\end{array}$ & 2,88 & $<0,05$ & 1,11 & $>0,05$ \\
\hline
\end{tabular}

ніж у дівчат. Виняток становлять результати школярів 7 8-го класів. Достовірність відмінностей $(p<0,05)$ спостерігалася в результатах школярів 10-го класу. У хлопців спостерігалися більш високі показники, ніж у дівчат (табл. 1)

Аналізуючи показники відчуття дотику на середині долоні у школярів в залежності від статі, робимо висновок, що у дівчат результати тактильної чутливості зазначеної ділянки шкіри, переважно, краще, ніж у хлопців, за винятком показників учнів 6, 7-го класів. Відмінності в результатах не достовірні ( $p>0,05)$ (табл. 1).

Отримані результатидослідження підтверджуютьдані О. О. Заварзіна, Р. В. Коз'якова, Н. Р. Коро, О. О. Орлова, Н. В. Ришлякова [3], які відмічають, що відмінності в показниках відчуття дотику на 3-ій фраланзі середнього пальця кисті та середини долоні у хлопців і дівчат середнього шкільного віку з вадами зору обумовлені тим, що пороги тактильної чутливості індивідуальні для кожної людини.

Порівняння результатів тактильної чутливості 3-ої фраланги середнього пальця кисті і середини долоні в учнів середніх класів з вадами зору з показниками, представленими В.П.Дегтеревим, Г.В. Кушнарьовою, Р.П. Фенькіною [2] для здорових людей, виявило, що вони нижче норми.

\section{Висновки /Дискусія}

Таким чином, проведене дослідження дало можливість визначити показники функціонального стану тактильного аналізатора у дітей середнього шкільного віку з вадами зору та сформулювати такі висновки:

1. Найкращі результати відчуття дотику на 3-ій фраланзі середнього пальця кисті виявлено у хлопців 10-го та дівчат 7-го класів; середині долоні - у хлопців 6-го та дівчат 9-го класів.

2. Показники тактильної чутливості 3-ої фраланги середнього пальця кисті, здебільшого, кращі у хлопців; середини долоні - у дівчат.

3. Показники фрункціонального стану тактильного аналізатора в учнів середніх класів з вадами зору нижче норми.

Перспективи подальших досліджень у даному напрямку полягають у дослідженні показників фрункціонального стану інших сенсорних систем у дітей середнього шкільного віку з вадами зору.

Конфллікт інтересів. Автори заявляють, що немає конфрлікту інтересів, який може сприйматися таким, що може нанести шкоду неупередженості статті.

Джерела фінансування. Ця стаття не отримала фінансової підтримки від державної, громадської або комерційної організації.

\section{Список посилань}

1. Абдулаев, А., Моисеенко, Е. К. (2017), "Изменение показателей технической подготовленности и фрункционального состояния тактильного анализатора волейболистов 12-13 лет на протяжении годичного макроцикла", Спортивные игры, № 3, С. 4-7.

2. Дегтерев, В. П., Кушнарёва, Г.В., Фенькина, Р.П. и др. (1988), Руководство к практическим занятиям по физиологии: Учеб. Пособие, Под ред. Г.И. Косицкого, В. А. Полянцева, Медицина, Москва, 288 с.

3. Заварзина, О. О., Козъяков, Р. В., Коро, Н. Р., Орлова, Е. А., Рышлякова, Н. В. (2015), Психофизиологияпрофессиональной деятельности: Учебник и практикум для прикладного бакалавриата, Директ-Медиа, Москва-Берлин, 546 с.

4. Кузьменко, І. О. (2013), Розвиток координаційних здібностей школярів середніх класів з урахуванням фрункціонального стану сенсорних функцій: Автореф. дис. на здобуття наукового ступеня канд. наук з фіз. вих. та спорту: спец. 24.00 .02 - «Фізична культура, фізичне виховання різних груп населення», ХДАФК, Харків, 20 с.

5. Маркова, Т. О., Репш, Н. В. (2013), Сенсорные системы человека: Учебное пособие, ФГАОУ ВПО ДВФУ (Школа педагогики), Уссурийск, Ч. І, 36 с.

6. Моисеенко, Е. К. (2014), "Влияние специально направленных упражнений на функциональное состояние сенсорных систем и двигательную подготовленность детей дошкольного возраста", Спортивные игры, № 10, С. 91-97.

7. Ножкина, Т. В., Пивоварова, И. А., Прусова, Н. В. (2017), Общая психология: Учебное пособие [Электронная книга], 470 с 8. Ровний, А. С. (2001), "Механізм сенсорного контролю точних рухів спортсменів протягом тренувального заняття", Теорія методика фрізичного виховання і спорту, № 1, С. 31-34. 


\section{СЛОБОЖАНСЬКИЙ НАУКОВО-СПОРТИВНИЙ ВІСНИК:}

\section{Матеріали XIX Міжнародної науково-практичної конференції «Фізична культура, спорт і здоров'я: стан, проблеми та перспективи»}

9. Claussen, C. F., Franz, B. (2006), Contemporary and practical neurootology, Solvay, Hannover, $410 \mathrm{p}$.

10. Maslyak, I. (2015), "Influence of specially directed exercises on separate functions of sensor-based systems of pupils of junior classes", Slobozhanskyi herald of science and sport, № 5 (49), P. 48-51.

11. Ropper, A. H., Brown, R. H. (2005), Adams and Victor's principles of neurology - eighth edition, McGraw-Hill, Chicago, San Francisco, New York, 1384 p.

12. Shesterova, L., Riadova, L., Masliak, I. (2018), "A change of the tactile analyser functional state indicators of 10-16 year old pupils with visual impairment under the influence of specially directed exercises and outdoor games", Sport science : International scientific journal of kinesiology, Travnik, Bosnia and Herzegovina, Vol. 11. Issue 2. P. 25-32.

Стаття надійшла до редакції: 11.11 .2019 p

Опубліковано: 30.12.2019p

Аннотация. Лилиана Рядовая. Исследование показателей функционального состояния тактильного анализатора у детей среднего школьного возраста с нарушениями зрения Цель: определить показатели фрункционального состояния тактильной сенсорной системы у учащихся средних классов с нарушениями зрения. Материал и методы: показатели тактильной чувствительности определялись по методу естезиометрии. В исследовании приняли участие школьники средних классов с нарушениями зрения коммунального учреждения «Харьковская специальная общеобразовательная школа-интернат IIII ступеней № 12» Харьковского областного совета для детей с нарушениями зрения. Результаты: рассматривались показатели тактильной чувствительности 3-й фаланги среднего пальца кисти и середины ладони у детей среднего школьного возраста с нарушениями зрения. Выводы: выявлено, что лучшие показатели тактильной чувствительности на 3-ей фаланге среднего пальца кисти наблюдались у мальчиков 10-го и девочек 7-го классов; середины ладони - у мальчиков 6-го и девочек 9го классов.

Ключевые слова: дети, нарушения зрения, средний школьный возраст, тактильная чувствительность, фрункциональное состояние тактильного аналізатора, чувство прикосновения.

Abstract. Liliana Riadova. The study of indicators of the functional state of the tactile analyzer in children of secondary school age with visual impairment Purpose: to determine the indicators of the functional state of the tactile sensory system in the middle-school students with the visual impairments. Material and methods: indicators of the tactile sensitivity were determined by the method of the esthesiometry. In the study involved the pupils of the middle classes with the visual impairments of the community establishment "Kharkov Special Boarding School I-III degree № 12» of the Kharkov Regional Council for children with the visual impairments. Results: the considered indicators of the tactile sensitivity the 3rd phalanx the middle finger of the arm and of the middle palm in the middle school children with the visual impairments. Conclusions: it was revealed that the best indicators of tactile sensitivity on the 3rd phalanx of the middle finger of the arm were observed in boys of the 10th and girls of the 7th grade; of the middle of the palm - in boys of the 6th and girls of the 9th grade.

Keywords: children, functional state of the tactile analyzer, middle school age, sense of touch, tactile sensitivity, visual impairment.

\section{References}

1. Abdulaev, A. \& Moiseenko, Ye. K. (2017), "The changes of the indicators of the technical preparedness and functional state of the tactile analyzer of the volleyball players of 12-13 years during a one-year macrocycle", Sportivnye igry, № 3, C. 4-7. (in Russ.)

2. Claussen, C. F. \& Franz, B. (2006), Contemporary and practical neurootology, Solvay, Hannover, $410 \mathrm{p}$.

3. Degterev, V.P., Kushnareva, G. V. \& Fenkina, R. P.i dr. (1988), Rukovodstvo k prakticheskim zanyatiyam po fiziologii [Physiology practice guide], Meditsina, Moskva. (in Russ.)

4. Kuzmenko, I. O. (2013), Rozvytok koordynatsiinykh zdibnostei shkoliariv serednikh klasiv z urakhuvanniam funktsionalnoho stanu sensornykh funktsii [Development of the coordination abilities of the schoolchildren of the middle classes taking into account the functional state of the sensory functions: thesis abstract]: Avtoref. dys. na zdobuttia naukovoho stupenia kand. nauk z fiz. vykh. ta sportu: $24.00 .02-$

«Fizychna kultura, fizychne vykhovannia riznykh hrup naselennia», KhDAFK, Kharkiv. (in Ukr.)

5. Markova, T.O. \& Repsh, N. V.(2013), Sensornye sistemy cheloveka[Human sensory systems], FGAOU VPO DVFU (Shkola pedagogiki), Ussuriysk. (in Russ.)

6. Maslyak, I. (2015), "Influence of specially directed exercises on separate functions of sensor-based systems of pupils of junior classes", Slobozhanskyi herald of science and sport, № 5 (49), P. 48-51.

7. Moiseenko, Ye. K. (2014), "The influence of the specially directed exercises on the functional state of the sensory systems and motor fitness of the preschool children", Sportivnye igry, № 10, C. 91-97. (in Russ.)

8. Nozhkina, T. V., Pivovarova, I. A. \& Prusova, N. V. (2017), Obshchaya psikhologiya [General psychology]. (in Russ.)

9. Ropper, A. H. \& Brown, R. H. (2005), Adams and Victor's principles of neurology - eighth edition, McGraw-Hill, Chicago, San Francisco, New York, $1384 \mathrm{p}$.

10. Rovnyi, A. S. (2001), "The mechanism of sensory control of precise movements of athletes during training", Teoriia $i$ metodyka fizychnoho vykhovannia i sportu, № 1, C. 31-34. (in Ukr.)

11. Shesterova, L., Riadova, L. \& Masliak, I. (2018), "A change of the tactile analyser functional state indicators of 10-16 year old pupils with visual impairment under the influence of specially directed exercises and outdoor games", Sport science : International scientific journal of kinesiology, Travnik, Bosnia and Herzegovina, Vol. 11. Issue 2. P. 25-32.

12. Zavarzina, O. O., Kozyakov, R. V., Koro, N. R., Orlova, Ye. A. \& Ryshlyakova, N. V. (2015), Psikhofiziologiya professionalnoy deyatelnosti[Psychophysiology of professional activity], Direkt-Media, Moskva-Berlin. (in Russ.)

Received: 11.11.2019.

Published: 30.12 .2019

\section{Відомості про авторів / Information about the Authors}

Рядова Ліліана Олегівна: Харківська державна академія фрізичної культури: вул. Клочківська, 99, м. Харків, 61058, Україна Рядовая Лилиана Олеговна: к. физ. восп., доцент; Харьковская государственная академия фриической культуры: ул. Клочковская, 99 г. Харьков, 61058, Украина.

Liliana Riadova: PhD (Physical Education and Sport); Assosiate Professor, Kharkiv State Academy of Physical Culture: Klochkivska str. 99, Kharkiv, 61058, Ukraine.

ORCID.ORG/0000-0003-4574-2246

E-mail: Lil1ana@mail.ru 